\title{
O SEMANTICOCENTRISMO DE RONALD LANGACKER RONALD LANGACKER'S SEMANTICOCENTRISM
}

\author{
Gustavo Augusto Fonseca Silva ${ }^{1}$
}

\begin{abstract}
Resumo: Para Ray Jackendoff, os modelos linguísticos desenvolvidos por Noam Chomsky distorcem a natureza da linguagem devido a seu "sintaticocentrismo". Por esse termo, Jackendoff entende a premissa adotada por Chomsky desde o modelo padrão da gramática gerativa (Aspectos da teoria da sintaxe) até o Programa Minimalista de que o componente sintático é proeminente em relação aos componentes fonológico e semântico, que seriam tão somente interpretativos. O próprio Jackendoff, no entanto, também observa que desde ao menos os anos 1970 muitos pesquisadores cometeram o erro oposto ao de Chomsky por negar à sintaxe um papel gramatical relevante. Considerando-se esse quadro, analisa-se neste artigo a gramática cognitiva de Ronald Langacker, na qual a sintaxe é substituída pela semântica como componente linguístico central. O objetivo é mostrar como Langacker contrapôs o sintaticocentrismo chomskiano com uma espécie de "semanticocentrismo". Ao fazê-lo, conforme se detalha neste trabalho, acabou por também deturpar gravemente a constituição da linguagem.
\end{abstract}

Palavras-chave: Semanticocentrismo de Ronald Langacker; sintaticocentrismo de Noam Chomsky; arquitetura paralela de Ray Jackendoff.

Abstract: Ray Jackendoff understands that Noam Chomsky's linguistic models distort the nature of language due to syntactocentrism. Coined by Jackendoff, the term "syntactocentrism" represents Chomsky's assumption, from standard theory in Generative Grammar (Aspects of the Theory of Syntax) to Minimalist Program, that syntactic components are central while phonological and semantic components are merely interpretive. However, Jackendoff himself also states that since the 1970s, while denying that syntax plays a relevant role in grammar many researchers made a mistake opposite to Chomsky's. Considering such a scenario, this article analyzes Ronald Langacker's Cognitive Grammar, which claims semantics instead of syntax is a central linguistic component. The goal is to demonstrate how Langacker counteracts Chomsky's syntactocentrism through "semanticocentrism". By doing so he gravely misrepresents language structure, as detailed in this work.

Keywords: Ronald Langacker's semanticocentrism; Noam Chomsky's syntactocentrism; Ray Jackendoff's parallel architecture.

\section{INTRODUÇÃO}

No artigo "Some problems for biolinguistics", de 2014, o linguista Derek Bickerton mostra-se um tanto cético quanto ao novo campo de pesquisas da linguagem

\footnotetext{
${ }^{1}$ Doutor em Linguística Teórica e Descritiva pela Universidade Federal de Minas Gerais (UFMG). Brasil. fonsecaugusto@hotmail.com

Orcid: http://orcid.org/0000-0001-7427-4504
} 
que vem sendo denominado "biolinguística". Isso porque, para Bickerton, a relação entre a biolinguística - entendida como "o estudo da biologia da linguagem" (JENKINS, 2013, p. 4) - e o Programa Minimalista, de Noam Chomsky (1999 [1995]), é “ambígua” (p. 73), "criando dúvidas se [a biolinguística] é uma subdisciplina genuína ou simplesmente outro nome para uma teoria linguística particular" (ibid.) - qual seja, o minimalismo chomskiano. De fato, tais dúvidas, compartilhadas por linguistas e não linguistas (ibid.), são pertinentes, dado que Chomsky, o pai fundador da gramática gerativa e o principal proponente das teorias linguísticas que culminaram na biolinguística, afirma categoricamente que o Programa Minimalista é "o próximo estágio natural da investigação biolinguística" (2007a, p. 2; 2007b, p. 14). Essa posição e suas implicações, no entanto, são questionáveis e realmente vêm sendo questionadas há anos pelo trabalho de autores como Peter Culicover (1999), Talmy Givón (2002) e Ray Jackendoff (1997, 2003, 2007, 2010, 2011a, 2011b, 2014).

A chamada "arquitetura paralela" de Jackendoff, em especial, apresenta-se como um promissor "programa de pesquisa" (LAKATOS, 1979 [1970]; 1995 [1978]) biolinguístico alternativo ao minimalismo de Chomsky por estar livre de seu "sintaticocentrismo". ${ }^{3}$ Por esse termo, Jackendoff entende a premissa adotada desde os primórdios do gerativismo e mantida até o Programa Minimalista de que o componente sintático é proeminente em relação aos componentes fonológico e semântico, que seriam tão somente interpretativos (JACKENDOFF, 1997, p. 15). Contrário à arquitetura sintaticocêntrica de Chomsky (2015 [1957], 1975 [1965], 1981a, 1994 [1986], 1999 [1995]), na qual "as regras de formação fonológicas e semânticas são nulas, de modo que tudo nas estruturas fonológicas e semânticas é determinado apenas por suas interfaces com a sintaxe" (JACKENDOFF, 2007, p. 50), Jackendoff vem elaborando nas últimas três décadas sua arquitetura paralela. Nesse quadro teórico, a linguagem é vista como uma estrutura organizada em sistemas combinatórios semi-independentes - sintaxe, fonologia e semântica -, cada qual com seus próprios princípios organizacionais, que geram interfaces entre si, mas sem qualquer protagonismo sintático, fonológico ou semântico. De fato, como bem observa Jackendoff (2007, p. 66), "uma arquitetura sintaticocêntrica não apresenta semelhança alguma com o resto da mente/cérebro". Isto é, "não se conhece paralelo ao 'sistema computacional' mestre que gera estruturas sintáticas, o qual por sua vez determina estruturas fonológicas e significados" (ibid.). A visão, exemplifica Jackendoff (ibid., p. 65), é um sistema cognitivo típico: é formada por muitas áreas cerebrais independentes, cada qual especializada em algum aspecto visual, como forma, movimento, cor e relações espaciais. E todas essas áreas têm interfaces umas com as outras, sem haver uma área em que tudo se centraliza para formar uma representação completa do campo visual. "Isso tem precisamente o cheiro de uma arquitetura paralela em linguística, em que a noção de 'sentença' ou 'frase' é distribuída entre várias estruturas, comunicando-se com cada uma via interfaces específicas", argumenta Jackendoff (ibid.). ${ }^{4}$

Essa concepção da linguagem como uma arquitetura paralela, no entanto, contraria não apenas os modelos sintaticocêntricos de Chomsky, mas também uma série de modelos "semanticocêntricos", nos quais a sintaxe é substituída pela semântica como o componente central da linguagem. Entre os modelos semanticocêntricos, a gramática cognitiva de Ronald Langacker (1987, 1991a, 1991b) sobressai tanto por seu pioneirismo, remontando aos anos 1970, quanto pelo modo consistente com que seu autor a desenvolve

\footnotetext{
${ }^{2}$ As traduções foram feitas pelo autor.

${ }^{3}$ Para uma defesa pormenorizada dessa posição, ver Silva (2020).

${ }^{4}$ Para uma análise comparativa detalhada entre a arquitetura paralela de Jackendoff e o minimalismo de Chomsky, ver Silva (2020).
} 
há décadas. Em vista disso, a fim de reiterar a maior adequação empírica da arquitetura paralela de Jackendoff em relação a quadros teóricos rivais (gerativistas e não gerativistas), é imprescindível rediscutir as ideias linguísticas de Langacker. Neste artigo, ainda que de forma um tanto limitada, leva-se a cabo essa tarefa. O intuito ao fazê-lo vale dizer - não é descartar a gramática cognitiva como um todo, e sim remover dela os exageros cometidos por Langacker em seu ataque sem tréguas (e frequentemente infundado) ao gerativismo chomskiano. Feito esse expurgo, espera-se que as ideias de Langacker possam ser incorporadas às discussões biolinguísticas - em particular, àquelas relativas ao componente semântico da linguagem.

\section{AS RAÍZES GERATIVISTAS DA GRAMÁTICA COGNITIVA}

No fim dos anos 1960, uma cortina de ferro desceu sobre a gramática gerativa. De um lado, Chomsky e seus seguidores desenvolviam a chamada teoria padrão, sintetizada pelo próprio Chomsky nos Aspects of the theory of syntax (Aspectos da teoria da sintaxe), de 1965. De outro, um grupo de dissidentes liderado por Paul Postal, James McCawley, John "Háj" Ross e George Lakoff, todos ex-alunos de Chomsky, propunha uma nova vertente teórica, que seria denominada de semântica gerativa. Nela, alguns dos pilares da teoria padrão foram atacados, com destaque à hipótese da autonomia da sintaxe em relação à semântica. Em contra-ataque, Chomsky e seus partidários golpearam o pontochave da semântica gerativa: a hipótese de que a estrutura profunda é a própria representação semântica. Tendo extrapolado a mera divergência científica, as discussões entre os dois grupos intensificaram-se tanto que posteriormente seriam batizadas de "guerras linguísticas" (HARRIS, 1993; NEWMEYER, 1996). A despeito do furor dos envolvidos, que muitas vezes se ofendiam pessoalmente, os confrontos foram relativamente breves. No fim dos anos 1970, já era claro à comunidade linguística que Chomsky e seus companheiros haviam derrubado as principais ideias dos semanticistas gerativistas - em especial sua concepção do componente semântico - e, consequentemente, saíam vencedores do conflito. No entanto, como em todo pós-guerra, as sequelas daqueles embates perdurariam por muitos anos. Na realidade, mesmo hoje os efeitos nocivos daquelas batalhas ainda se fazem sentir tanto na gramática gerativa quanto na linguística cognitiva, que, derivando da semântica gerativa, carrega em seu DNA a marca de oposição ao gerativismo. De fato, como ressalta Peter Harder (2007, p. 1248), desde o início, "a linguística cognitiva estava muito ciente de ser tudo o que a gramática gerativa não era: não formal, não modular, não baseada em condições de verdade e assim por diante". Considerando-se esse papel de antagonista ao gerativismo assumido pela linguística cognitiva, fica nítida a importância de voltar às raízes gerativistas desse programa de pesquisa para melhor entender seus fundamentos, bem como seus equívocos.

Antes de mais nada, é preciso sublinhar que a semântica gerativa essencialmente recusava a hipótese chomskiana da autonomia da sintaxe em relação à semântica e identificava a estrutura profunda com a representação semântica. "O cerne da semântica gerativa era uma obliteração do limite sintaxe-semântica no nível mais profundo da gramática - o axioma de que a estrutura profunda real era a representação semântica, não um input sintático para o componente semântico", sintetiza Randy A. Harris (1993, p. 105). O modelo teórico de Paul Postal (1972), intitulado Homogeneous I, talvez seja a formulação mais bem desenhada dessa ideia. De forma um tanto simplificada, pode-se dizer que, para Postal, no lugar da estrutura profunda, no sentido de Chomsky (1975 [1965]), há o conteúdo semântico da sentença, que é associado ao pensamento não linguístico. Este, por sua vez, após ser submetido a transformações, aproximadamente no 
sentido de Chomsky (1975 [1965]), resultaria na sentença propriamente dita. Assim, se de um lado Chomsky insistia que a sintaxe é independente da semântica, afirmando por exemplo que "a relação entre sintaxe e semântica (...) pode ser estudada apenas depois que a estrutura sintática tenha sido determinada em bases independentes" (CHOMSKY, 2015 [1957], p. 23, n. 4), por outro os semanticistas gerativistas, como Postal, argumentavam que a sintaxe só pode ser investigada considerando-se sua relação com o componente semântico. Portanto, diferentemente de Chomsky, que atribuía à semântica o papel de tão somente interpretar o sentido das sentenças formadas na derivação puramente sintática, os semanticistas gerativistas defendiam que a semântica também era um componente gerativo, não apenas a sintaxe. Ironicamente, o que levou os semanticistas gerativistas a esse posicionamento foi a radicalização de um pressuposto teórico assumido nos Aspectos da teoria da sintaxe: a chamada hipótese Katz-Postal, segundo a qual a estrutura profunda determina completamente o sentido (KATZ; POSTAL, 1964). Levada às últimas consequências por Postal, Lakoff, Ross e McCawley, essa hipótese resultou na ideia de que a estrutura profunda $e ́$ o sentido.

Em sua entrevista a Mitsou Ronat no fim dos anos 1970, na qual Ronat já podia dizer com segurança que a semântica gerativa àquela altura estava "virtualmente abandonada" (CHOMSKY, 1977, p. 135), Chomsky resumiu suas divergências em relação a essa corrente teórica e rebateu as principais críticas que lhe foram feitas por seus adeptos, sobretudo em relação ao componente semântico da linguagem. Na ocasião, Chomsky enfatizou que desde o início do gerativismo dava à semântica um lugar central, opondo-se apenas à ideia de que a sintaxe é baseada na semântica (ibid., p. 126-127). "Sempre neguei e rejeitei de modo explícito uma posição completamente diferente, a qual com frequência me foi erroneamente atribuída: ou seja, que o estudo do sentido, da referência e da utilização da linguagem está fora do campo da linguística", afirmou Chomsky (ibid., p. 127). "Seria absurdo supor que tal teoria linguística inata [a teoria da gramática universal], que determina a forma geral da estrutura da linguagem, não estivesse ligada da maneira mais íntima às propriedades fundamentais do sentido e da utilização" (ibid., p. 128). Especificamente em relação à ideia defendida pela semântica gerativa de que a estrutura profunda é o sentido, Chomsky comentou:

\begin{abstract}
Na realidade, o modelo padrão tal como o apresentaram em Aspectos foi contestado desde o início. Por um lado, fora observado no próprio livro (que estava no prelo em 1964) que pelo menos alguns aspectos da representação semântica (por exemplo, os que estão ligados ao foco e ao tema [tópico]) pareciam estar mais relacionados com a estrutura superficial que com a estrutura profunda. ${ }^{5} \mathrm{~A}$ pesquisa ulterior sobre o papel da estrutura superficial na determinação do sentido de uma frase levou à teoria padrão ampliada [estendida] (ibid., p. 137-138).
\end{abstract}

Com efeito, ainda no âmbito da teoria padrão, Chomsky e Halle (1968, p. 6-7) já afirmavam que a estrutura superficial tinha algum papel na determinação semântica. Na teoria padrão estendida, por sua vez, foi proposto que, diferentemente do que havia sido defendido antes, a estrutura superficial também determina o sentido. Essa mudança de perspectiva, é claro, representou um problema fatal à semântica gerativa. De qualquer maneira, conforme Chomsky, a melhor crítica à teoria padrão não foi a feita pelos semanticistas gerativistas, e sim aquela feita por Jackendoff em meados dos anos 1960:

\footnotetext{
${ }^{5}$ Ver Chomsky (1975 [1965], p. 319, n. 32 e p. 323, n. 9). Na nota 9 da página 323, a propósito, Chomsky cita as famosas sentenças "Everyone in the room knows at least two languages" (Todos na sala sabem ao menos duas línguas) e "At least two languages are known by everyone in the room" (Ao menos duas línguas são sabidas por todos na sala) para ilustrar o fato de que transformações afetam o sentido de determinadas sentenças. Ver Lemle (1984, p. 29ss) e Guimarães (2017, p. 215ss), por exemplo, para uma discussão detalhada desta questão.
} 
"Mostrou ele que a estrutura superficial desempenha na interpretação semântica um papel muito mais importante do que se supunha, conclusão que falseava a hipótese padrão segundo a qual só a estrutura profunda recebia uma tal interpretação" (CHOMSKY, 1977, p. 138). As evidências que Jackendoff apresentou para sustentar essa posição derivavam de sentenças com foco e pressuposição e de sentenças com negação e quantificadores. No primeiro caso, Jackendoff demonstrou que fenômenos fonológicos - portanto, em estrutura superficial - como entonação, acento (stress) e altura (pitch) estão relacionados ao componente semântico. Veja-se um exemplo retirado de Jackendoff (1980 [1972], p. 229):

(1a) Is it JOHN who writes poetry? (É o JOÃO que escreve poesia?)

(1b) No, it is BILL who writes poetry. (Não, é o BILL que escreve poesia.)

(1c) No, it is JOHN who writes short stories. (Não, é o JOÃO que escreve contos.)

Como observa Jackendoff (ibid.), (1b) é uma resposta "natural" para (1a), mas não (1c). Isso porque, detalha Jackendoff (ibid., p. 230), em (1a) pressupõe-se que alguém escreve poesia, ou seja, o falante assume que essa informação é compartilhada por ele e pelo ouvinte. "John", por sua vez, é o foco da sentença, isto é, o falante assume que essa informação não é compartilhada por ele e pelo ouvinte. Mas tanto aquilo que é pressuposto quanto aquilo que é focalizado na sentença são denotados fonologicamente e, portanto, não são informações semânticas contidas em estrutura profunda. Com isso, desmente-se a hipótese Katz-Postal.

No segundo caso, Jackendoff evidenciou que o conteúdo semântico de sentenças com negação e quantificadores pode ser alterado com operações de transformação, o que igualmente derruba a hipótese Katz-Postal. Em "Pedro chutou a bola" e "A bola foi chutada por Pedro", por exemplo, a operação de passivização não altera o conteúdo semântico das sentenças, determinado na estrutura profunda. Dessa forma, esses exemplos atestam a hipótese Katz-Postal de que o sentido é completamente determinado em estrutura profunda. As sentenças (2), no entanto, apresentadas por Jackendoff (ibid., p. 325-326), refutam essa generalização:

(2a) Not many of the arrows hit the target. (Não muitas das flechas atingiram o alvo.)

(2b) Many of the arrows didn't hit the target. (Muitas das flechas não atingiram o alvo.)

(2c) The target wasn't hit by many of the arrows. (O alvo não foi atingido por muitas das flechas.)

Com base na hipótese Katz-Postal, argumenta Jackendoff (ibid., p. 326), a sentença passiva (2c) deveria ser ambígua, expressando o conteúdo semântico tanto da sentença (2a) como da sentença (2b). No entanto, a única interpretação possível de (2c) é sinônima de (2a) - a não ser que se enfatize a palavra "many" (muitas). Dessa maneira, as sentenças $(2 a),(2 b)$ e $(2 c)$ representam mais um contraexemplo fatal à hipótese KatzPostal e, consequentemente, à sua radicalização feita na semântica gerativa de que a estrutura profunda é o sentido.

Para não deixar margem a dúvidas quanto à vitória da sua vertente teórica sobre a semântica gerativa, Chomsky chama a atenção ainda de Ronat para a então nova teoria dos traços, chegando a afirmar com base nela que "toda a semântica, inclusive as relações temáticas, está ligada à estrutura superficial" (1977, p. 150) e que, "com a teoria dos traços, podemos dizer que somente a estrutura superficial está ligada à representação semântica" (ibid., p. 156). Vale lembrar que na teoria padrão assumia-se que os papéis temáticos (agente, paciente, instrumento, etc.) eram atribuídos na estrutura profunda. 
Conforme a teoria dos traços, porém, o papel temático é deslocado junto com o nome. Veja-se um exemplo dado por Chomsky a Ronat (ibid., p. 151):

\section{(3) A quem Pedro ensina latim $t$ ?}

Em (3), o papel temático de objetivo, atribuído ao sintagma preposicional "a quem" em estrutura profunda, desloca-se junto com ele até a topicalização em estrutura superficial. Assim, conclui Chomsky (ibid., p. 150-151), com a teoria dos traços é possível atribuir a relação temática à estrutura superficial, em vez de atribuí-la à estrutura profunda.

Todos esses argumentos contrários à semântica gerativa apresentados por Chomsky e por seus discípulos nunca foram devidamente respondidos pelos semanticistas gerativistas. Por isso, a despeito de Lakoff ter declarado a vitória da semântica gerativa em 1973 (HARRIS, 1993, p. 197), Givón não exagerava ao dizer poucos anos depois que o movimento da semântica gerativa já era àquela altura "história antiga" (GIVÓN, 1979, p. 19). Compartilhando dessa interpretação, Harris (1993, p. 215) explica que, mais do que seus ataques à semântica gerativa, foram as possibilidades de pesquisa abertas por suas novas propostas teóricas que levaram Chomsky a vencer a "guerra linguística" contra os semanticistas gerativistas já nos anos 1970. É importante, porém, acrescentar a essa análise o fato de que, independentemente dos avanços teóricos na gramática gerativa, a semântica gerativa, que pouco a pouco acabou sob a liderança de Lakoff, já havia caído em descrédito naquele período em determinados círculos teóricos por conta de seus próprios excessos - originados e divulgados, em grande medida, por Lakoff. "Com Lakoff ao leme", pontua Harris (ibid., p. 227-8), "promovendo sua muito ampla concepção de teoria linguística (...), a percepção geral se tornou de que a semântica gerativa era promíscua teoricamente, incapaz de dizer não." Na verdade, com Lakoff à sua frente, a semântica gerativa supostamente iria englobar

\footnotetext{
não apenas sintaxe-semântica, fonética-fonologia, linguística histórica, linguística antropológica, etc., que formam o núcleo da maioria dos programas acadêmicos neste país, mas também o papel da linguagem em interação social, em literatura, em ritual e em propaganda, assim como o estudo da relação entre linguagem e pensamento, produção e percepção de fala, transtornos linguísticos, etc. (Lakoff, in Parret, 1974 [1972], p. 151 apud HARRIS, 1993, p. 228).
}

Como ironizou Harris (ibid.), "fica-se com a impressão de que Lakoff parou a lista mais porque ele ficou sem fôlego do que porque ele ficou sem visão, cuidadosamente lembrando-se de jogar aquele etc. antes de tomar algum ar". Dessa forma, "a semântica gerativa sob Lakoff tentou fazer muito, ficando por fim sem pé nem cabeça" (ibid.). A propósito, para Harris (ibid., p. 230), dois traços em particular talvez tenham sido decisivos para a debacle da semântica gerativa: "sua abrangência de uma ampla gama de interesses e sua autodefinição primária na retórica dissidente, em dizer não a Chomsky". Nos dois casos, mesmo não tendo sido uma voz solitária entre os semanticistas gerativistas, Lakoff certamente foi a mais estridente. Para piorar sua situação individual, como bem recorda Newmeyer (1996, p. 126), nesse período Lakoff apresentava praticamente de ano em ano uma nova teoria - ao menos um novo nome de teoria -, como a "fuzzy grammar" (1973), a "global transderivational well-formedness grammar" (1974), a "cognitive grammar" (1975), a "dual-hierarchy grammar" (1975), a "linguistic gestalt theory" (1977) e a "experimental linguistics" (1977). Apesar de todas essas teorias terem em comum uma oposição visceral ao gerativismo chomskiano, nenhuma delas despertou muito interesse entre os críticos de Chomsky. Talvez porque elas sempre foram vistas mais como um amontoado de observações do que como um quadro teórico bem 
definido. Isso, porém, iria mudar radicalmente em 1980, com a publicação do livro Metaphors we live by por Lakoff em parceria com o filósofo Mark Johnson. Nessa obra, considerada um dos marcos inaugurais da linguística cognitiva, Lakoff e Johnson defendem a ideia de que as metáforas não são meros floreios literários ou estilísticos, e sim um recurso linguístico tão poderoso a ponto de estruturar a linguagem, a percepção da realidade, o pensamento e as ações humanas - daí a alegação de que vivemos por metáforas. Discutir os pormenores dessa teoria fugiria aos propósitos deste trabalho. ${ }^{6}$ Deve-se, porém, destacar que, ao defenderem esse papel central das metáforas na cognição humana, Lakoff e Johnson retomaram em um novo molde o velho ataque feito pelos semanticistas gerativistas à hipótese da autonomia da sintaxe. De fato, indo muito além de uma rejeição a esse pilar da linguística chomskiana, Lakoff e Johnson - assim como os cognitivistas de modo geral - reavivaram em novos termos a teoria, defendida anteriormente por expoentes como o psicólogo Jean Piaget (e.g. 1952, 1971, 1975 [1923]), de que a linguagem deriva da inteligência geral, não havendo portanto um "módulo mental" específico para ela - isto é, uma faculdade da linguagem, nos termos de Chomsky (e.g. 1994 [1986], 1999 [1995]). ${ }^{7}$

Seguindo os passos de Lakoff e Johnson, Ronald Langacker, que foi uma figura periférica na semântica gerativa (HARRIS, 1993, p. 251), saltaria ao primeiro plano da linguística cognitiva alguns anos depois do lançamento de Metaphors we live by ao propor nos dois volumes de Foundations of cognitive grammar (1987, 1991a) uma teoria linguística que igualmente rejeita a hipótese da autonomia da sintaxe e a existência de uma faculdade da linguagem.

\section{DO SINTATICOCENTRISMO DE CHOMSKY AO SEMANTICOCENTRISMO DE LANGACKER}

Com efeito, tendo Lakoff e Langacker à frente do movimento, a linguística cognitiva, cujo "ponto fundacional é simplesmente que a linguagem é toda sobre significado" (GEERAERTS, 2006b, p. 3), posicionou-se desde o início como uma antítese ao gerativismo chomskiano. $\mathrm{Na}$ realidade, dando continuidade à semântica gerativa e em resposta ao sintaticocentrismo de Chomsky, a linguística cognitiva definiuse prontamente como "uma franca tentativa de dar ao significado uma posição central na arquitetura da gramática" (ibid., p. 27). Como consequência dessa postura antagônica ao gerativismo, porém, a linguística cognitiva acabou por adotar pressupostos teóricos que não condizem com as evidências empíricas advindas da própria linguística e de ciências afins, como a psicologia, a biologia e as neurociências. Sua visão não modular da mente humana, em particular, parece insustentável à luz dos avanços científicos das últimas décadas. A título de exemplo, com uma teoria modular da mente humana, segundo a qual a mente/cérebro é dividido em unidades (ou módulos), cada qual responsável por uma determinada atividade cognitiva (FODOR, 1983; LENNEBERG, 1967; MARR, 1982), é possível explicar por que crianças pequenas desenvolvem em relativo pouco tempo complexas habilidades linguísticas (e.g. CRAIN, 1991, 2012; CRAIN; NAKAYAMA, 1987; CRAIN; PIETROSKI, 2001; CRAIN; THORNTON, 2012; MILLOTTE et al., 2013; PINKER, 1984 e 1989), mas não outras habilidades cognitivas, como as necessárias para inferir as intenções, crenças e desejos de outras pessoas, as quais levam muito mais

\footnotetext{
6 Para uma análise específica dos excessos cometidos por Lakoff e Johnson em sua teoria "metaforocêntrica", ver Silva (2021).

${ }^{7}$ Para acesso ao famoso debate entre Chomsky e Piaget ocorrido em 1975, ver Piattelli-Palmarini (1983 [1980]).
} 
tempo até atingir um estágio avançado, conforme mostram testes clássicos de teoria da mente (e.g. BARON-COHEN; LESLIE; FRITH, 1985; BARON-COHEN, 1995). Uma teoria modular da mente humana também permite explicar mais satisfatoriamente casos de patologias ou distúrbios neurológicos, como afasias, autismo, síndrome de Turner e síndrome de Williams, nos quais há diferenças significativas entre os danos à linguagem e os danos a outras habilidades cognitivas (e.g. BOONE; PLANTE, 1994; CURTISS, 2013; MARSHALL, 1990; MARCUS et al., 2013; SMITH; TSIMPLI, 1995; PIATTELLI-PALMARINI, 2013). Uma teoria modular da mente humana possibilita ainda entender melhor casos de lesões cerebrais decorrentes por exemplo de derrames, nos quais é comum haver grandes diferenças entre os danos à linguagem e os danos a outras habilidades cognitivas, como o reconhecimento facial, a memória e a percepção de formas e de imagens, a depender da região cerebral atingida (e.g. DE AGUIAR et al., 2015; SINANOVIĆ et al., 2011).

Outra consequência negativa da postura antagônica dos cognitivistas em relação aos gerativistas é a escassez de diálogo entre os proponentes dos dois campos de pesquisas. Exceção a essa (quase) regra, Jackendoff vale-se criticamente das propostas teóricas de ambos os lados, rejeitando tanto os excessos do sintaticocentrismo chomskiano como os excessos do semanticocentrismo cognitivista. Na verdade, estando ciente dos malefícios advindos da polarização entre a gramática gerativa e a linguística cognitiva, Jackendoff (2003, p. 269) destaca que essa situação tem suas raízes exatamente nas guerras linguísticas dos anos 1960 e 1970. Voltando àquele período, Jackendoff (ibid.) avalia que, com o surgimento da semântica gerativa, os chomskianos abandonaram de vez o estudo sistemático do significado, deixando o assunto a teóricos de outras áreas, como a semântica formal, a psicologia cognitiva e, mais tarde, a linguística cognitiva. Fato notório, muitos dos representantes desses campos de estudos sempre rejeitaram veementemente a gramática gerativa por conta de sua pouca atenção à semântica. Ao rejeitá-la, lamenta Jackendoff (ibid.), vários desses pesquisadores acabaram caindo no erro oposto ao do gerativismo, negando à sintaxe qualquer papel relevante na gramática. Dessa forma, a abordagem teórica desses autores, em especial dos cognitivistas, "minimiza ou mesmo elimina as regras de formação sintática, de modo que a sintaxe é determinada inteiramente pela significação" (JACKENDOFF, 2007, p. 50). Em outras palavras, ao combater o sintaticocentrismo, muitos cognitivistas "foram para o outro extremo e negaram à sintaxe qualquer papel independente" (ibid., p. 43), sendo por isso ignorados pelos gerativistas. Para complicar, acrescenta Jackendoff (ibid., p. 194), diferentemente da gramática gerativa, a linguística cognitiva não está "muito preocupada em integrar seus resultados com o resto da psicologia", sendo "mais cética a respeito da necessidade de uma noção independente da sintaxe na capacidade linguística". Contrário a essa postura, Jackendoff ( ibid., p. 52) enfatiza que a sintaxe tem seu lugar na arquitetura paralela, já que é esse componente que determina aspectos gramaticais elementares como concordância verbal e formação de orações relativas e interrogativas. Particularidades sintáticas como essas, arremata Jackendoff (ibid.) em sua investida contra o semanticocentrismo, têm de ser aprendidas pelas crianças, mas não são previsíveis pela semântica.

É curioso, porém, que, ao criticar os excessos da linguística cognitiva, Jackendoff não cite nenhuma das muitas pesquisas feitas nas últimas décadas por biólogos, psicólogos e neurocientistas em favor de uma teoria modular da mente humana. Também é curioso que Jackendoff não mencione o fato de que, contrariando Lakoff e Langacker, o terceiro dos "pais fundadores" (GEERAERTS; CUYCKENS, 2007a, p. 8) da linguística cognitiva, Leonard Talmy, não somente afirma que o sistema semântico é um dos sistemas cognitivos (2000, I, p. 4) como assume um "modelo de sistemas sobrepostos" 
(ibid., p. 15) da cognição humana, no qual diferentes sistemas cognitivos, próprios à linguagem, à percepção, à razão, à memória, ao controle motor, etc., têm propriedades estruturais unicamente deles; propriedades adicionais que compartilham com apenas um ou com alguns outros sistemas cognitivos e propriedades fundamentais que têm em comum com todos os outros sistemas cognitivos. Ou seja, um modelo modular da mente humana, com semelhanças nítidas com a arquitetura paralela. Na verdade, com base em evidências empíricas como as citadas acima, pode-se dizer que o modelo modular de Talmy é cientificamente mais sólido que o modelo não modular de Lakoff e Johnson e de Langacker. Levando isso em consideração, saltam aos olhos os equívocos cometidos por Langacker na elaboração de sua gramática cognitiva.

Como esclarece o próprio Langacker (2007, p. 422; 2008, p. 7; 2010, p. 89), a gramática cognitiva é parte da linguística cognitiva e esta da tradição funcionalista. Entre os pressupostos centrais da gramática cognitiva, informa Langacker, estão 0 entendimento de que a linguagem é uma faceta integral da cognição humana e não um módulo específico (2007, p. 422); a ideia de que a análise semântica e a análise gramatical não se separam (ibid., p. 423) e a compreensão de que não há limites entre estruturas linguísticas e estruturas não linguísticas (ibid., p. 425; 1987, seção 2.1.2). Em reconhecimento a semelhanças da gramática cognitiva com outros quadros teóricos, Langacker (2007, p. 421) pontua que a gramática cognitiva, assim como a semântica gerativa, trata o léxico, a semântica e a gramática de modo unificado e que, como a gramática de construções, vê o léxico e a gramática como um continuum de construções. Além disso, dando voz a seu semanticocentrismo, Langacker (1987, p. 12) fundamenta a gramática cognitiva nos pressupostos de que "significado é aquilo sobre o que a linguagem inteiramente diz respeito" e de que "a gramática é simplesmente a estruturação e simbolização de conteúdo semântico" (ibid.).

Essa concepção semanticocêntrica da linguagem defendida por Langacker esbarra, no entanto, em dificuldades aparentemente intransponíveis. Para começar, tratar o léxico, a semântica e a gramática de modo unificado resulta em sérios problemas mesmo para a análise de aspectos elementares da linguagem. Uma comprovação tão trivial quanto expressiva desse fato encontra-se na velha distinção entre gênero biológico (ou "semântico") e gênero gramatical (cf., p. ex., ARNAULD; LANCELOT, 2001 [1660], II, V; CORBETT, 1991; GREENBERG, 1978a; PAUL, 1983 [1880], § 181-184; UNTERBECK et al., 2000). Com efeito, se a gramática fosse simplesmente a estruturação e simbolização de conteúdo semântico - isto é, se a gramática fosse inteiramente motivada semanticamente -, não poderia haver diferenças de gênero gramatical entre as línguas. Assim, em hipótese alguma substantivos masculinos em determinada língua poderiam ser substantivos femininos em outra língua. Não é difícil, no entanto, encontrar ocorrências dessa discrepância. Em português, por exemplo, são masculinos os substantivos "o número", "o jornal" e "o rato", enquanto em alemão esses mesmos substantivos são femininos: "die Zahl”, "die Zeitung" e "die Maus". Outro problema quanto à distinção entre gênero biológico e gênero gramatical que se impõe à gramática cognitiva decorre da existência do gênero neutro em algumas línguas, como a alemã, mas não em outras, como a portuguesa. Com isso, se os substantivos "das Auto", "das Buch" e "das Mehl" são neutros em alemão, em português eles necessariamente precisam ser classificados em masculinos ou femininos, a despeito de não terem, é claro, um gênero biológico: "o carro", "o livro", "a farinha". Para complicar o quadro, como se sabe, o gênero neutro não é empregado apenas com substantivos inanimados nas línguas em que existe, e nem todo substantivo inanimado é do gênero neutro nessas línguas. Em alemão mesmo, os substantivos “das Mädchen" ("a menina"), "das Fräulein" ("a senhorita"), "das Kätzchen” (“o gatinho"), “das Kamel” (“o camelo") e "das Pferd” (“o cavalo"), por 
exemplo, recebem o gênero neutro, apesar de se referirem a seres vivos. Já os substantivos "die Wahrheit" ("a verdade"), "die Frage" ("a pergunta"), "die Philosophie" ("a filosofia"), "der Sommer" (“o verão"), "der Wein" (“o vinho") e "der Raum” (“o espaço", "o lugar"), entre tantos outros, pertencem nessa língua ou ao gênero feminino ou ao gênero masculino, ainda que sejam abstratos ou inanimados. Assim, considerando-se todos esses casos, que evidentemente poderiam ser estendidos com facilidade abrangendo muitas outras línguas, só se pode concluir ser imprecisa a ideia defendida por Langacker de que a análise semântica e a análise gramatical não se separam, bem como inviável o seu projeto de tratar o léxico, a semântica e a gramática de modo unificado.

Não convencido, porém, de que a discrepância entre gênero biológico e gênero gramatical é um obstáculo incontornável à sua gramática cognitiva - ou seja, não convencido de que põe abaixo seu projeto de pesquisa o fato de que a classificação de grande parte do léxico "é opaca semanticamente e deve simplesmente ser aprendida como uma convenção gramatical" (LANGACKER, 1991b, p. 181) -, Langacker tenta mostrar como, "ao menos em princípio" (ibid., p. 180), é possível lidar com esse fenômeno de um ponto de vista cognitivista. Para isso, Langacker propõe tratar os contraexemplos lexicais ao pressuposto de que a gramática é motivada semanticamente como "unidades convencionais" (ibid., p. 183). Primeiramente, Langacker observa que uma classe típica de substantivos apresenta algo como uma organização prototípica (ibid., p. 181), na qual alguns exemplares são mais representativos do que outros. Para ilustrar esse ponto, Langacker (ibid., p. 182) recorre ao espanhol, chamando atenção para o fato de que "el hombre" ("o homem"), "el hijo" ("o filho") e "el perro" ("o cachorro") são exemplares prototípicos de substantivos masculinos nessa língua, enquanto "la mujer" ("a mulher"), "la hija" ("a filha") e "la perra" ("a cachorra") são exemplares prototípicos de substantivos femininos na mesma língua. Passando a casos em que um substantivo inanimado recebe gênero masculino ou feminino em língua espanhola, como "el palo" (“o pau"), "el sudor" (“o suor"), "la mesa" (“a mesa") e "la puerta" (“a porta"), Langacker (ibid., p. 182-183) afirma se tratar de exemplares não prototípicos, que o falante deve aprender como "unidades convencionais". "Pressupõe-se que essas classes são definidas gramaticalmente em vez de semanticamente", afirma Langacker (ibid., p. 183), contrariando as premissas basilares da gramática cognitiva. "O comportamento de um substantivo não pode ser predito por seu significado - falantes devem aprender especificamente, para cada substantivo individual, com qual artigo ele ocorre", completa. Dessa forma, conforme Langacker, os exemplares prototípicos de substantivos têm o gênero motivado semanticamente, mas não os exemplares não prototípicos, que são semanticamente opacos.

No livro Cognitive grammar: a basic introduction, de 2008, Langacker torna a abordar o problema que representa à sua teoria a discrepância entre gênero biológico e gênero gramatical, argumentando que "as classes gramaticais têm variados graus de motivação semântica” (p. 334). Segundo Langacker (ibid.), de um lado, há categorias universais, como as de substantivo e de verbo, que têm uma base conceitual; de outro, existem classes sem caracterização semântica alguma - as "classes distribucionais" (ibid., p. 335) -, como os substantivos da língua inglesa cuja terminação em $f$ muda para $v$ no plural: wife/wives, leaflleaves, etc. Entre um extremo e outro, sustenta Langacker (ibid., p. 334), estaria a maioria das classes, inclusive as de gênero (ibid., p. 337). Com o intuito de justificar seu posicionamento, Langacker (ibid., p. 337-338) retoma a ideia de que os exemplares prototípicos das categorias de gênero são motivados semanticamente, ainda que os exemplares não prototípicos não o sejam. Assim, após reconhecer a arbitrariedade do gênero de palavras alemãs como a masculina Löffel ("colher"), a feminina Gabel ("garfo") e a neutra Messer ("faca"), Langacker volta ao espanhol reafirmando a 
prototipicidade de substantivos masculinos como hombre ("homem"), hijo ("filho") e tío ("tio"), bem como a prototipicidade de substantivos femininos como mujer ("mulher"), hija ("filha") e tía ("tia"), os quais seriam motivados semanticamente.

Um primeiro inconveniente que se pode apontar à argumentação de Langacker é sua circularidade. Isso porque, de acordo com Langacker, um exemplar prototípico de uma classe masculina ou feminina têm o gênero semanticamente motivado. Mas qual o critério utilizado por Langacker para identificar determinado exemplar como prototípico? Sua suposta motivação semântica. Além disso, a argumentação de Langacker em si mesma é falha e refutável. Para corroborar essa afirmação, basta retomar a análise sobre o gênero neutro na língua alemã, na qual exemplares teoricamente prototípicos de substantivos não têm o gênero motivado semanticamente. "Das Mädchen" ("a menina"), apenas para dar um exemplo que já se tornou uma espécie de lugar-comum nas discussões sobre as incongruências entre gênero biológico e gênero gramatical, seguindo o raciocínio de Langacker, deveria necessariamente receber o gênero gramatical feminino ("die"), não podendo jamais receber o gênero neutro ("das"). Dado que é exatamente isso o que ocorre em alemão, porque o sufixo "-chen" é sempre associado ao gênero neutro nessa língua, fica vazia a alegação de Langacker de que o gênero, ao menos dos substantivos prototípicos, é semanticamente motivado. Como consequência dessa situação, que se torna ainda mais complicada considerando-se a alta produtividade de substantivos inanimados nas mais diversas línguas e a existência das "classes distribucionais", perde totalmente o sentido a ideia-chave da gramática cognitiva de que "significado é aquilo sobre o que a linguagem inteiramente diz respeito" (grifo nosso). Estendendo-se a discussão a outros aspectos da gramática cognitiva, torna-se claro que o mesmo problema relativo às classes de gênero perpassa toda a obra de Langacker. Ao investigar os conceitos elementares de substantivo e de verbo, por exemplo, Langacker (ibid., p. 14) afirma que substantivos prototípicos são "objetos físicos discretos" e que verbos prototípicos são as "interações energéticas" de tais objetos. Para deixar mais claro o ponto de vista de Langacker, vale observar que ele parte do pressuposto de que nós, seres humanos, pensamos sobre o mundo como o "modelo de bola de bilhar" (ibid., p. 13). Segundo esse modelo, esclarece Langacker (ibid.), nós pensamos sobre o mundo como algo povoado de objetos físicos discretos. Esses objetos são capazes de se mover pelo espaço e de fazer contato uns com os outros, sendo o movimento deles dado por sua energia interna ou pela energia que eles recebem externamente. "Esse modelo popular arquetípico exerce uma influência poderosa tanto no pensamento cotidiano quanto no pensamento científico, e sem dúvidas reflete aspectos fundamentais de organização cognitiva", aposta Langacker (ibid.), sem apresentar evidência empírica alguma de que as coisas sejam assim. De qualquer maneira, sem se deter pela falta de embasamento científico ao "modelo de bola de bilhar", Langacker (ibid., p. 15) sugere que objetos físicos e "interações energéticas" servem como os respectivos protótipos de substantivo e de verbo. Dessa forma, ambas as categorias seriam motivadas semanticamente, em conformidade com os pressupostos teóricos adotados na gramática cognitiva. No entanto, é elementar que muitos substantivos e muitos verbos não partilham das características desses supostos protótipos, como o reconhece o próprio Langacker (ibid.). Portanto, assim como uma infinidade de substantivos de línguas como a espanhola não têm o gênero motivado semanticamente, uma infinidade de substantivos e de verbos das línguas as mais diversas tampouco são motivados semanticamente. Contudo, novamente sem se deter diante desse entrave a sua teoria, e mais uma vez sem apresentar evidência empírica alguma, Langacker (ibid.) assegura que "se deve esperar que categorias universais de tamanha significância gramatical tenham uma base conceitual" - isto é, uma base semântica. 
No ensaio "Conceptualization, symbolization, and grammar", de 1998, Langacker reafirma sua análise cognitivista de substantivos e de verbos, mas desta vez admite: "Eu não tenho nenhuma prova definitiva dessa caracterização conceitual de substantivos. (...) Ela é meramente oferecida como uma proposta coerente. (...) Eu pessoalmente acho difícil imaginar que categorias fundamentais e universais como substantivos e verbos não tenham uma base conceitual" (LANGACKER, 1998, p. 19). Em feliz comentário a essa afirmação, Jackendoff (2003, p. 124, n. 12) confessa: "Eu acho seguro considerar isso simplesmente uma declaração de ideologia". De fato, considerando-se o modo precário com que Langacker defende a ideia de que substantivos e verbos têm uma base conceitual, seu posicionamento soa mais como o resultado de uma visão ideológica do que científica. Reitera essa impressão a admissão feita pelo próprio Langacker no mesmo ensaio das amplas limitações de sua teoria conceitualista das classes gramaticais:

A alegação de que tais classes são suscetíveis a descrições semânticas esquemáticas válidas para todos os membros é especificamente voltada para classes básicas e universais como substantivos e verbos, para suas maiores subclasses (e.g. substantivos contáveis vs substantivos não contáveis) e para algumas outras classes do tipo "partes do discurso" (como adjetivos, adposições e tipos específicos de particípios). Não é definitivamente afirmado que toda classe que um linguista possa propor com legitimidade seja definível dessa maneira. Essa alegação seria obviamente insustentável para muitas classes distribucionais constituídas de itens lexicais convencionalmente autorizados a participar de determinado padrão sintático, morfológico ou até mesmo fonológico. Mesmo quando uma construção tem uma base semântica, e seus itens lexicais exibem algum grau de coerência semântica (como nas passivas da língua inglesa), o inventário exato é frequentemente determinado convencionalmente e não totalmente predizível. O pertencimento a algumas classes (e.g. a classe dos verbos que têm uma forma irregular de passado) pode ser totalmente arbitrária (p. 23).

Contrário à inconsistente ideologia semanticocêntrica de Langacker, Jackendoff (2003, p. 124-125) sublinha que os substantivos têm em comum não uma base semântica, mas sim características sintáticas, como a possibilidade de ocorrer em posições típicas relacionadas a verbos e preposições; a capacidade de governar concordância de número e de gênero e de receber caso morfológico nas línguas que têm essa propriedade; a habilidade de ocorrer com expressões quantificacionais como "muito" (much), "muitos" (many) e "todos" (all); e assim por diante. Mas não persuadido por essa linha argumentativa, Langacker (e.g. 2007, 2008, 2010, 2013) segue defendendo sua "alegação teórica central" de que "a estrutura gramatical é inerentemente simbólica e que todas as construções gramaticais válidas têm algum tipo de importância conceitual" (1991b, p. 282). No entanto, dado que Langacker nunca conseguiu sequer mostrar que "noções (...) fundamentais para a gramática" (ibid., p. 313) como substantivos e verbos têm uma base conceitual - para não mencionar os contraexemplos que ele mesmo reconhece haver a sua gramática cognitiva -, deduz-se que sua "alegação teórica central" é tão somente mais uma declaração de ideologia.

Considerando-se todas essas questões relativas aos alicerces da gramática cognitiva, tornam-se mais do que compreensíveis as críticas feitas por Jackendoff a abordagens semanticocêntricas como a de Langacker, que minimizam ou mesmo eliminam as regras de formação sintática, fazendo com que a sintaxe seja determinada inteiramente pela significação e, consequentemente, perca sua independência. Além disso, estendendo o argumento de Jackendoff à fonologia, pode-se dizer que uma abordagem teórica como a de Langacker igualmente minimiza ou mesmo elimina as regras de formação fonológica, fazendo com que a fonologia seja determinada inteiramente pela significação e, por conseguinte, também perca sua independência. Mas, como as particularidades sintáticas, as particularidades fonológicas - a começar pelos 
sistemas consonantal e vocálico de uma língua - não são previsíveis pela semântica e têm de ser aprendidas pelos falantes. Estando, porém, aparentemente alheio a esse debate, Langacker segue afirmando há décadas que a linguagem inteiramente diz respeito ao significado. Não se trata, contudo, de um caso isolado entre os cognitivistas, que de modo geral só estão preocupados com fenômenos semânticos (NUYTS, 2007, p. 550). Em vista disso, não admira que o próprio Langacker (2007, p. 443) reconheça que a fonologia na gramática cognitiva é tão somente programática; que Margareth H. Freeman (2007, p. 1193) afirme que a fonologia cognitiva ainda está "em sua infância" e que John R. Taylor (2003, p. 265) pondere que "os tratamentos da linguística cognitiva a questões fonológicas são ainda incipientes". Na verdade, para Taylor (2007, p. 580), a fonologia tem sido negligenciada pelos cognitivistas porque as unidades fonológicas (fonemas, sílabas, pés, etc.) não têm conteúdo conceitual e portanto não podem ser reduzidas a uma questão de estrutura conceitual e sua simbolização, como se afirma na gramática cognitiva. Seja como for, o fato é que os estudos fonológicos na linguística cognitiva são tão precários que o capítulo sobre o tema publicado no Oxford handbook of cognitive linguistics é essencialmente um resumo da história da fonologia no século 20 que se inicia prenunciando "como uma fonologia cognitiva se parecerá" (NATHAN, 2007, p. 611). Mal mencionado nesse texto - assim como nos livros-textos Cognitive phonology in construction grammar, publicado em 2005 por Riitta Välimaan-Blum, e Phonology: a cognitive grammar introduction, publicado em 2008 pelo mesmo Geoffrey S. Nathan -, o ensaio "Cognitive phonology", que Lakoff apresentou na Berkeley Conference on Nonderivational Phonology de 1989, acabou se tornando uma espécie de precursor de expectativas não cumpridas de uma fonologia cognitiva propriamente dita - se é que isso é possível. O título do trabalho soa como um rótulo vazio porque as ideias nele defendidas não parecem ter relação alguma com a linguística cognitiva. Talvez por isso mesmo, nem o próprio Lakoff deu continuidade àquelas reflexões, que, no fim das contas, acabaram incorporadas à teoria gerativista da otimalidade de Prince e Smolensky (1993).

Mais relevante, porém, do que especular sobre os motivos que levaram Lakoff a abandonar seu projeto de uma fonologia cognitiva é lembrar que também em 1989 Sylvain Bromberger e Morris Halle publicaram o influente artigo "Why phonology is different", no qual restabelecem as diferenças entre a fonologia, de um lado, e a sintaxe e a semântica, de outro. Motivou-os a escrever esse trabalho a tentativa de alguns autores de manter a "unidade geral da teoria gramatical" (CHOMSKY, 1975 [1965], p. 168), estendendo à fonologia ganhos teóricos do modelo de princípios e parâmetros (CHOMSKY, 1981a e 1994 [1986]). A questão é que nos modelos padrão e padrão estendido, dos anos 1960 e 1970, havia transformações sintáticas ordenadas. Contudo, no modelo de princípios e parâmetros, que se consolidou no início dos anos 1980, as transformações foram abolidas em favor do princípio unificador mover $\alpha .{ }^{8}$ Dado o sucesso desse modelo e as vantagens de simplificar a teoria trocando as múltiplas transformações por um único princípio, logo se levantou a questão se não seria possível fazer algo parecido com a fonologia, substituindo suas muitas regras ordenadas por um princípio unificador. De acordo com Bromberger e Halle, a resposta só poderia ser não, porque na fonologia derivações baseadas em regras ordenadas e com estruturas intermediárias são essenciais, ao contrário do que acontece na sintaxe e na semântica. ${ }^{9}$ Para melhor justificar essa posição, Bromberger e Halle apresentam evidências tanto sincrônicas como diacrônicas de que o ordenamento de regras é algo inerente aos processos fonológicos e concluem que a ausência desse traço na sintaxe e na semântica

\footnotetext{
${ }^{8}$ Para uma discussão desse tópico, ver, por exemplo, Chomsky (1981a, 1994 [1986]).

9 Para exemplos desse ordenamento de regras relativos à fonologia do português brasileiro, ver, por exemplo, Bisol (2001).
} 
"é uma manifestação reveladora do fato de que representações tratadas pela fonologia diferem em natureza daquelas tratadas pela sintaxe/semântica" (p. 59).

\section{DOMÍNIOS DA ESTRUTURA LINGUÍSTICA, DOMÍNIOS COGNITIVOS}

Em relação especificamente às limitações da gramática cognitiva, é sintomático que Langacker nunca tenha tentado demonstrar que a sintaxe, a semântica e a fonologia são de alguma forma iguais, corroborando suas declarações de que a linguagem inteiramente diz respeito ao significado e que a gramática é simplesmente a estruturação e simbolização de conteúdo semântico. É igualmente sintomático que, apesar de afirmar que as alegações sobre a linguagem na gramática cognitiva devem ser compatíveis com as descobertas de disciplinas afins como a psicologia cognitiva, a neurociência e a biologia evolucionária (LANGACKER, 2007, p. 423), Langacker jamais tenha se deixado influenciar pelas muitas evidências empíricas que essas e outras disciplinas vêm acumulando há décadas em favor da modularidade da mente humana e da existência de algo como uma faculdade da linguagem. De fato, dado o número astronômico dos trabalhos com esses resultados - centenas dos quais são citados em manuais e coletâneas de linguística, neurolinguística, psicolinguística, biolinguística e temas correlatos (e.g. ARONOFF; REES-MILLER, 2006; BOECKX; GROHMANN, 2013; PIATTELIPALMARINI; BERWICK, 2013; TRAXLER; GERNSBACHER, 2006) -, seria inviável mencionar aqui mesmo uma pequena fração deles. No entanto, ainda que deixando de fora trabalhos clássicos como os de Paul Broca e de Carl Wernicke sobre pacientes afásicos no século 19 (cf., p. ex., JACKENDOFF, 1993, p. 146ss; LENNEBERG, 1967, cap. 2) e restringindo a exposição a algumas poucas pesquisas feitas no período de atividade profissional de Langacker, já é possível pôr em dúvida sua afirmação.

Considerando que as reflexões de Langacker que o levariam a formular a gramática cognitiva tiveram início em 1976 (LANGACKER, 2007, p. 421; 2008, p. vii), um bom ponto de partida para esta discussão talvez seja recordar o famoso caso da garota Genie, que foi acompanhado por linguistas e psicólogos ainda na primeira metade dos anos 1970 (e.g. CURTISS et al., 1974; FROMKIN et al., 1974). Como se sabe, Genie passou boa parte da infância sem contato com outras pessoas e, em decorrência disso, sua capacidade linguística jamais amadureceu plenamente. Além disso, como é também sabido, ao ser exposta a um ambiente normal aos 13 anos, Genie desenvolveu rapidamente a habilidade de falar sobre o mundo, distinguindo perfeitamente noções como a de passado, presente e futuro; animado e inanimado; físico e mental; atual e condicional. No entanto, sua habilidade linguística permaneceu precária, com uma sintaxe elementar, praticamente restrita à justaposição de itens lexicais básicos, apesar de ela ter adquirido um bom vocabulário. Tendo em vista esse quadro, os pesquisadores que trabalhavam com Genie concluíram que sua condição exemplificava com clareza como é possível que uma pessoa tenha um sistema cognitivo de modo geral rico, mas um sistema linguístico extremamente limitado - neste caso, devido à falta de exposição a uma língua no "período crítico" de aquisição da linguagem (LENNEBERG, 1967).

Em 1981, no mesmo ano em que Langacker publicou no artigo "The integration of grammar and grammatical change" os primeiros resultados de sua pesquisa iniciada em 1976 (LANGACKER, 2007, p. 421), Susan Curtiss e Jeni Yamada descreveram no artigo "Selectively intact grammatical development in a retarded child" um caso inverso ao de Genie, no qual um indivíduo com um sistema cognitivo de modo geral pobre apresentava um sistema linguístico rico. Segundo Curtiss e Yamada, o menino Antony tinha um QI na casa de 50 (a média é 100). Não obstante isso, sua sintaxe era muito bem 
desenvolvida, com recursos complexos como o movimento de constituintes e o uso de orações subordinadas. De acordo com os autores, Antony também empregava corretamente as classes sintáticas, além de demonstrar conhecimentos morfológicos avançados, como a marcação adequada de casos. No entanto, ponderam Curtiss e Yamada, Antony cometia erros semânticos e pragmáticos bizarros, a ponto de ser incapaz de fazer inferências elementares a partir de diálogos extremamente simples. Essa discrepância entre os sofisticados conhecimentos morfossintáticos de Antony e seus pobres conhecimentos semântico-pragmáticos, concluíram as pesquisadoras, comprovava não apenas que a mente é de fato modular, mas também que o componente sintático é independente do componente semântico.

Naquele mesmo ano, Curtiss publicou ainda outro trabalho que apontava para conclusões semelhantes. No artigo "Dissociations between language and cognition: cases and implications", Curtiss relata casos de crianças, como Genie e o mesmo Antony, que mostravam diferenças nítidas entre suas habilidades linguísticas e suas habilidades cognitivas não linguísticas. Com base nos estudos feitos com essas crianças, Curtiss afirmou haver evidências robustas de que a gramática é um sistema cognitivo autônomo e que as habilidades semânticas e lexicais estão profundamente conectadas com um desenvolvimento conceitual mais amplo, diferentemente das habilidades sintáticas e morfológicas. Dada essa disparidade entre os componentes gramaticais, Curtiss inferiu que o desenvolvimento de um sistema linguístico normal, em que a gramática está adequadamente conectada à significação, requer tanto o desenvolvimento linguístico quanto o desenvolvimento cognitivo não linguístico.

Yamada também publicaria outras pesquisas semelhantes à do menino Antony, com destaque ao livro Laura: a case for the modularity of language, de 1990. Segundo Yamada, Laura, que havia sido diagnosticada retardada com 1 ano de idade, tinha QI na casa dos 40. Já no fim da adolescência, quando o estudo foi realizado, Laura não conseguia fazer coisas simples como dizer as horas ou a sua idade, ler, contar ou resolver problemas simples. Porém, assim como Antony, apresentava uma habilidade linguística altamente desenvolvida, semelhante à de uma pessoa sem deficiência mental (p. 3-7). Sua sintaxe e sua morfologia, como no caso de Antony, eram bem desenvolvidas, o que se revelava pelo uso correto de recursos sofisticados como sentenças passivas e orações subordinadas (p. 27-35). No entanto, também como Antony, Laura tinha dificuldades semânticas consideráveis, sendo incapaz de entender o significado de muitas palavras corriqueiras, como "endereço", ou de empregar os números para contagens básicas (p. 39-62). Em vista das características de Laura, cuja única habilidade cognitiva desenvolvida era a linguística (p. 107), Yamada não apenas ratifica o modelo modular da mente humana (p. 6) como afirma de modo taxativo: “O perfil de Laura desafia a conceitualização da gramática como semanticamente baseada e a noção de que a sintaxe depende da semântica" (p. 112).

Muitos trabalhos posteriores ao de Yamada também desafiariam teorias linguísticas não modulares e semanticocêntricas como a de Langacker. No livro de 1995 The mind of a savant: language learning and modularity, por exemplo, Neil Smith e Ianthi-Maria Tsimpli apresentam amplas evidências que corroboram as conclusões a que haviam chegado Curtiss e Yamada. Nessa obra, relata-se o caso do autista savant Christopher Taylor. Aos 29 anos, Taylor tinha idade mental de 9,2 anos e QI de 56 (p. 4). Sua habilidade numeral era inferior à de uma criança de 5 anos (p. 5). Contudo, Taylor lia, escrevia, traduzia e se comunicava, em diferentes graus de competência, em 15 a 20 idiomas, entre os quais alguns tão díspares como grego moderno, russo, finlandês e holandês. Nos testes linguísticos a que foi submetido, Taylor obteve resultados acima da média (100) não apenas em sua língua materna, o inglês (121), mas também em alemão 
(114) e em francês (110) (p. 8). Porém, como Antony e Laura, Taylor apresentava limitações semânticas e pragmáticas não características de falantes nativos de inglês (p. 63ss), incluindo deficiências típicas de autistas, como dificuldades de compreender piadas, ironias e metáforas (p. 74ss). "A condição de Christopher é corretamente caracterizada em termos de um módulo linguístico intacto coexistindo com um sistema central afetado", afirmam Smith e Tsimpli (p. 67). Considerando o desnível entre a competência morfossintática de Taylor e sua competência semântico-pragmática, e assumindo a teoria modular de Jerry Fodor (1983), Smith e Tsimpli defendem haver um "módulo da linguagem" na mente/cérebro humano. Além disso, levando em conta os testes linguísticos que realizaram com Taylor, Smith e Tsimpli levantam a hipótese de que a representação sintática e a representação fonológica são completamente internas ao módulo da linguagem, enquanto a interpretação pragmática envolve esse módulo e sistemas mentais centrais, não modulares, nos quais conhecimentos gerais $\mathrm{e}$ enciclopédicos são armazenados (p. 30).

Não obstante a consistência e expressividade desses e de outros tantos estudos similares, Langacker, assim como a maioria dos cognitivistas, ignora seus resultados em sua obra. Sem rebater as conclusões a que pesquisadores como Curtiss, Yamada, Smith e Tsimpli chegaram em seus trabalhos, e sem apresentar pesquisas com conclusões diferentes das deles, Langacker, por exemplo, reitera no livro Cognitive grammar: a basic introduction sua concepção não modular da linguagem (p. 4 e p. 8) e seu ataque à hipótese chomskiana da autonomia da sintaxe (p. 5-6). Como se não fosse o bastante esse completo desdém pelas evidências empíricas favoráveis à modularidade da mente humana e à autonomia da sintaxe, Langacker abre o primeiro capítulo da obra declarando que a gramática cognitiva é "intuitivamente natural, psicologicamente plausível e empiricamente viável” (p. 3). Em suas demais publicações, Langacker adota uma postura semelhante, o que compreensivelmente o levou a enfrentar sérios contratempos. A título de exemplo, no livro Grammar and conceptualization, de 1999, Langacker reafirma que "a gramática e o significado estão indissociáveis" (p. 1), ponderando ainda que "a linguagem necessariamente engloba estruturas semânticas, estruturas fonológicas e ligações simbólicas entre as duas", sendo "a alegação central" da gramática cognitiva que "nada mais é necessário" (ibid.). No mesmo livro, contudo, Langacker cita a semântica, a fonologia, o léxico, a morfologia e a sintaxe como "todos os domínios da estrutura linguística" (p. 121), o que evidentemente sinaliza haver outras coisas necessárias à linguagem além das estruturas semânticas, estruturas fonológicas e ligações simbólicas entre as duas. Tentando desfazer a confusão, Langacker argumenta:

\begin{abstract}
A GC [gramática cognitiva] mesma oferece unificação conceitual. Ela postula apenas estruturas semântica, fonológica e simbólica. Léxico, morfologia e sintaxe formam uma gradação que se considera completamente descritível como conjuntos de estruturas simbólicas. A distinção entre regras gramaticais e expressões simbolicamente complexas é apenas uma questão de se (ou em que grau) os conjuntos simbólicos que as constituem são esquemáticos em vez de específicos. Enquanto há alguma tendência para que as regras morfológicas e sintáticas difiram em termos de generalidade e produtividade, a única base consistente para distingui-las é se a composição fonológica que elas especificam acontece dentro de uma palavra ou envolve sequências de palavras. Expressões construídas de acordo com esquemas gramaticais também podem ser de qualquer tamanho. Com o uso repetido, uma expressão de qualquer tamanho ou grau de composicionalidade pode estar enraizada e convencionalizada. O léxico de uma língua é então definível como um conjunto de expressões com o status de unidades convencionais (p. 122).
\end{abstract}

A exposição que se segue, assim como a de outros textos de Langacker, incluindo o abrangente Cognitive grammar: a basic introduction, também não ajuda muito a compreender sua alegação de que nada mais é necessário na linguagem além das 
estruturas semântica, fonológica e simbólica, apesar de o léxico, a morfologia e a sintaxe serem reconhecidos por ele como domínios da estrutura linguística ao lado da semântica e da fonologia. Essa constatação de que há lacunas consideráveis na teoria de Langacker é importante porque sinaliza como a morfologia, a fonologia e a sintaxe são subrepresentadas em sua gramática cognitiva - como de resto na linguística cognitiva -, sem explicações plausíveis sobre como fenômenos morfossintáticos e fonológicos elementares como concordância verbal, formação de orações relativas e interrogativas, harmonização vocálica e monotongação ${ }^{10}$ são motivados semanticamente. Sem essa subrepresentação, Langacker não poderia afirmar que a análise semântica e a análise gramatical não se separam; que não há limites entre estruturas linguísticas e estruturas não linguísticas e que a linguagem é uma faceta integral da cognição humana e não um módulo separado.

Comprovam essa análise declarações de Langacker como a de que, "até onde é possível, a linguagem é vista como recrutando fenômenos cognitivos mais gerais (e.g. atenção, percepção, categorização, memória) dos quais ela não pode ser desassociada" (LANGACKER, 2007, p. 422). Ora, esse "recrutamento" não permeia todo e qualquer aspecto linguístico. Para perceber isso, basta lembrar os casos Antony, Laura e Taylor. Além do mais, a afirmação de que existe na mente/cérebro humano um módulo específico à linguagem não implica, como Langacker parece acreditar, que esse módulo esteja completamente isolado dos outros módulos e de fenômenos cognitivos mais gerais. $\mathrm{Na}$ realidade, abundantes evidências empíricas desencorajam essa compreensão, a começar por aquelas levantadas por Curtiss, Yamada, Smith e Tsimpli em seus estudos, as quais vêm sendo reiteradas por outros pesquisadores (e.g. MARCUS et al., 2013). O próprio Chomsky, ainda nos primórdios da gramática cognitiva, já chamava a atenção para o fato de que a faculdade da linguagem não é um módulo mental desconectado do resto da mente/cérebro. Vale lembrar que, em Regras e representações, Chomsky reconhece que uma explicação mais completa do conhecimento linguístico deve levar em consideração as interações da gramática com outros sistemas, especialmente o sistema de estruturas conceptuais e o sistema de competência pragmática (p. 74). Na mesma obra, Chomsky enfatiza ainda que "o sistema linguístico é apenas um entre vários sistemas cognitivos que interagem intimamente no uso efetivo da linguagem" (p. 143) e que a linguagem é determinada pela interação de inúmeros sistemas internos que atuam sob condições de grande variedade e complexidade (p. 165). No entanto, apesar da clareza dessas afirmações, muitos linguistas cognitivistas, inclusive Talmy (2000, II, p. 376), vêm injustamente atribuindo a Chomsky a defesa da ideia de que os módulos são autônomos e não interagem entre si. Quanto a isso, Chomsky já se posicionava claramente no fim dos anos 1970, declarando que o modelo de análise de um sistema cognitivo, como a visão ou a linguagem, deve examinar a maneira pela qual ele é utilizado e como ele interage com outros sistemas cognitivos (CHOMSKY, 1977, p. 58 e p. 85). Sem deixar dúvidas sobre a sua opinião, que seria repisada muitas vezes ao longo das décadas seguintes, inclusive no contexto minimalista (e.g. CELA-CONDE; MARTY, 1998, p. 31), Chomsky já afirmava também que a linguagem recruta fenômenos cognitivos mais gerais:

Parece que outros sistemas cognitivos - particularmente nosso sistema de crenças sobre as coisas do mundo e seu comportamento - intervêm em nossos julgamentos do sentido e da referência, de maneira extremamente intrincada, e está longe de ser claro que haja sentido, mesmo em princípio, em tentar dissociar esses diversos componentes daquilo que, num uso informal ou mesmo numa

\footnotetext{
${ }^{10}$ Para uma análise desses e de outros fenômenos fonológicos no português brasileiro, ver, por exemplo, Bisol e Brescancini (2002).
} 
discussão técnica, chamamos de "o sentido de uma expressão linguística". Creio que não se pode separar a representação semântica do conhecimento do mundo (CHOMSKY, 1977, p. 130).

Em acordo com Chomsky, Langacker (1987, p. 63) afirma com toda a razão que "o significado de uma expressão tipicamente envolve especificações em muitos domínios cognitivos, alguns dos quais são muito mais centrais a seu valor do que outros". Desnecessário dizer que a menção a "muitos domínios cognitivos" subentende uma teoria modular da mente/cérebro.

\section{CONSIDERAÇÕES FINAIS}

Dadas as origens gerativistas da linguística cognitiva, bem como o fato de que décadas antes de seu surgimento a gramática gerativa já adotava uma abordagem cognitivista - isto é, mentalista (CHOMSKY, 1998, p. 21) - de estudo da linguagem (GEERAERTS, 2006b, p. 2; SILVA, 1997, p. 61), pode-se dizer que Jackendoff (2007, p. 35) não exagera tanto ao caracterizar a linguística cognitiva como uma corrente não chomskiana da gramática gerativa. Sem entrar em detalhes sobre essa avaliação, cabe destacar que a maioria das questões abordadas pelos cognitivistas não são novas (UNGERER; SCHMID, 1996, p. 280). Conscientes disso, pesquisadores como Dirk Geeraerts (1988, 1999, 2002), Brigitte Nerlich e David D. Clarke (2000, 2001, 2007) e Ulrike Schröder $(2004,2008,2014,2017)$ chamam a atenção para o fato de que a linguística cognitiva é, em boa medida, um retorno ao trabalho secular de uma série de linguistas das mais diversas escolas de pensamento, remontando mesmo à Grécia Antiga. Assim, "a perspectiva 'cognitiva' da linguagem não é nova, ao contrário do que alguns cognitivistas afirmam, nomeadamente Lakoff” (SILVA, 1997, p. 63). O que é novo na perspectiva cognitivista em relação à perspectiva de seus precursores é a apropriação indevida dos temas investigados por eles para atacar a gramática gerativa - em especial, as hipóteses gerativistas da autonomia da sintaxe e da modularidade da mente humana. Percebido esse ponto, transparece que a gramática gerativa e a linguística cognitiva são vertentes teóricas que podem e devem ser aproximadas, como aliás já defendem alguns autores, entre os quais o cognitivista John R. Taylor (2007, p. 583). Mais: percebidos e eliminados seus respectivos excessos sintaticocêntricos e semanticocêntricos, a gramática gerativa e a linguística cognitiva naturalmente se unem na arquitetura paralela de Jackendoff, cabendo respectivamente ao componente sintático e ao componente fonológico as teorias sintáticas e fonológicas desenvolvidas pelos gerativistas, e ao componente semântico as teorias semânticas desenvolvidas pelos cognitivistas inclusive, é claro, por Langacker. Em outros momentos na história das ideias linguísticas, essa divisão justificadamente pareceria uma banalidade. No cenário atual, porém, como consequência ainda em boa medida das guerras linguísticas dos anos 1960 e 1970, defendê-la é um grande desafio.

\section{AGRADECIMENTOS}

Gostaria de agradecer à professora doutora Ulrike Schröder (UFMG) pelas críticas, comentários e sugestões a uma versão anterior deste trabalho. Também gostaria de agradecer a dois pareceristas anônimos por suas valiosas observações, que muito contribuíram para o aperfeiçoamento deste texto. A responsabilidade pelas posições aqui assumidas, claro, é inteiramente minha. 


\section{REFERÊNCIAS}

ARNAULD, Antoine; LANCELOT, Claude. Gramática de Port-Royal, ou Gramática geral e razoada. 2. ed. São Paulo: Martins Fontes, 2001.

ARONOFF, Mark; REES-MILLER, Janie. The handbook of linguistics. 3. ed. Malden, MA: Blackwell, 2006.

BARON-COHEN, Simon. Mindblindness: an essay on autism and theory of mind. Cambridge, Mass.: MIT Press, 1995.

BARON-COHEN, S.; LESLIE A. M.; FRITH, U. Does the autistic child have a "theory of mind"? Cognition, v. 21, n. 1, p. 37-46, 1985.

BICKERTON, Derek. Some problems for biolinguistics. Biolinguistics, v. 8, p. 73-96, 2014.

BISOL, Leda (Org.). Introdução a estudos de fonologia do português brasileiro. 3. ed. Porto Alegre: Edipucrs, 2001.

BISOL, Leda; BRESCANCINI, Cláudia (Orgs.). Fonologia e variação: recortes do português brasileiro. Porto Alegre: EdiPUCRS, 2002.

BOECKX, Cedric; GROHMANN, Kleanthes K. The Cambridge handbook of biolinguistics. Cambridge: Cambridge University Press, 2013.

BOONE, Daniel R.; PLANTE, Elena. Comunicação humana e seus distúrbios. 2. ed. Porto Alegre: Artes Médicas, 1994.

BROMBERGER, Sylvain; HALLE, Morris. Why phonology is different. Linguistic Inquiry, v. 20, n. 1, p. 51-70, 1989.

CELA-CONDE, Camilo; MARTY, Gisèle. Noam Chomsky's Minimalist Program and the Philosophy of Mind. Syntax, v. 1, n. 1, p. 19-36, 1998.

CHOMSKY, Noam. Aspectos da teoria da sintaxe. Coimbra: Armenio Amado, 1975.

CHOMSKY, Noam. Biolinguistic explorations: design, development, evolution. International Journal of Philosophical Studies, v. 15, n. 1, p. 1-21, 2007a.

CHOMSKY, Noam. Diálogos com Mitsou Ronat. São Paulo: Cultrix, 1977.

CHOMSKY, Noam. Estruturas sintáticas. Petrópolis: Vozes, 2015.

CHOMSKY, Noam. Lectures on government and binding. Dordrecht: Foris, 1981a.

CHOMSKY, Noam. Linguagem e mente: pensamentos atuais sobre antigos problemas. Brasília: Editora Universidade de Brasília, 1998.

CHOMSKY, Noam. O conhecimento da língua: sua natureza, origem e uso. Lisboa: Caminho, 1994.

CHOMSKY, Noam. Of minds and language. Biolinguistics, v. 1, p. 9-27, 2007b.

CHOMSKY, Noam. O programa minimalista. Lisboa: Caminho, 1999.

CHOMSKY, Noam. Regras e representações: a inteligência humana e seu produto. Rio de Janeiro: Zahar, $1981 b$.

CHOMSKY, Noam; HALLE, Morris. The sound pattern of English. Nova York: Harper \& Row, 1968.

CORBETT, Greville G. Gender. Cambridge: Cambridge University Press, 1991.

CRAIN, Stephen. Language acquisiton in the absence of experience. Behavioral and Brain Science, v. 14, p. 597-650, 1991.

CRAIN, Stephen. The emergence of meaning. Cambridge: Cambridge University Press, 2012.

CRAIN, Stephen; NAKAYAMA, Mineharu. Structure dependence in grammar formation. Language, v. 63, n. 3, p. 522-543, 1987.

CRAIN, Stephen; PIETROSKI, Paul. Nature, nurture and Universal Grammar. Linguistics and Philosophy, v. 24, p. 139-185, 2001.

CRAIN, Stephen; THORNTON, Rosalind. Investigations in universal grammar: a guide to experiments on the acquisition of syntax and semantics. Cambridge, MA; Londres: MIT Press, 2012.

CULICOVER, Peter. Syntactic nuts: hard cases, syntactic theory, and language acquisition. Oxford: Oxford University Press, 1999.

CURTISS, Susan. Dissociations between language and cognition: cases and implications. Journal of Autism and Developmental Disorders, v. 2, n. 1, p. 15-30, 1981.

CURTISS, Susan. Revisiting modularity: using language as a window to the mind. In: PIATTELLIPALMARINI, Massimo; BERWICK, Robert C. (Eds). Rich languages from poor inputs. Oxford: Oxford University Press, 2013, p. 68-90.

CURTISS, Susan; YAMADA, Jeni. Selectively intact grammatical development in a retarded child. UCLA Working papers in cognitive linguistics, v. 3, p. 61-91, 1981. 
CURTISS, S.; FROMKIN, V.; KRASHEN, S.; RIGLER, D.; RIGLER, M. The linguistic development of Genie. Language, v. 50, n. 3, p. 528-554, 1974.

DE AGUIAR, Vânia; PAOLAZZI, Caterina Laura; MICELI, Gabriele. Tdcs in post-stroke aphasia: the role of stimulation parameters, behavioral treatment and patient characteristics. Cortex, v. 63, p. 296$316,2015$.

FODOR, Jerry. The modularity of mind: an essay on faculty psychology. Cambridge, MA: MIT Press, 1983.

FREEMAN, Margareth H. Cognitive linguistic approaches to literary studies. In: GEERAERTS, Dirk; CUYCKENS, Hubert (Eds.). The Oxford handbook of cognitive linguistics. Nova York; Oxford: Oxford University Press, 2007, p. 1175-1202.

FROMKIN, V.; KRASHEN, S.; CURTISS, S.; RIGLER, D.; RIGLER, M. The development of language in Genie: a case of language acquisition beyond "critical period". Brain and Language, v. 1, p. 81107, 1974.

GEERAERTS, Dirk. Cognitive grammar and the history of lexical semantics. In: RUDZKA, Brydiga (Ed.). Topics in cognitive linguistics. Amsterdã: Benjamins, 1988, p. 647-677.

GEERAERTS, Dirk. (Ed.). Cognitive linguistics: basic readings. Berlim; Nova York: Mouton de Gruyter, 2006a.

GEERAERTS, Dirk. Hundred years of lexical semantics. Atas do $1^{\circ}$ Encontro Internacional de Linguística Cognitiva. Porto, 1999, p. 123-154.

GEERAERTS, Dirk. Introduction: a rough guide to cognitive linguistics. In: GEERAERTS, Dirk (Ed.). Cognitive linguistics: basic readings. Berlim; Nova York: Mouton de Gruyter, 2006b, p. 1-28.

GEERAERTS, Dirk. The theoretical and descriptive development of lexical semantics. In: BEHRENS, Leila; ZAEFFERER, Dietmar (Eds.). The lexicon in focus: competition and convergence in current lexicology. Berna: Peter Lang Verlag, 2002, p. 23-42.

GEERAERTS, Dirk; CUYCKENS, Hubert. Introducing cognitive linguistics. In: GEERAERTS, Dirk; CUYCKENS, Hubert (Eds.). The Oxford handbook of cognitive linguistics. Nova York; Oxford: Oxford University Press, 2007a, p. 3-21.

GEERAERTS, Dirk; CUYCKENS, Hubert (Eds.). The Oxford handbook of cognitive linguistics. Nova York; Oxford: Oxford University Press, 2007b.

GIVÓN, Talmy. Bio-linguistics: The Santa Barbara Lectures. Amsterdã: John Benjamins, 2002.

GIVÓN, Talmy. On understanding grammar. Nova York; San Francisco; Londres: Academic Press, 1979.

GREENBERG, Joseph H. How does a language acquire gender markers? In: GREENBERG, Joseph H. (Ed.). Universals of human language. Vol. 3, Word Structure. Stanford: Stanford University Press, 1978a, p. 47-82.

GREENBERG, Joseph H. (Ed.). Universals of human language. Vol. 3, Word Structure. Stanford: Stanford University Press, 1978b.

GUIMARÃES, Maximiliano. Os fundamentos da teoria linguística de Chomsky. Petrópolis: Vozes, 2017.

HARDER, Peter. Cognitive linguistics and philosophy. In: GEERAERTS, Dirk; CUYCKENS, Hubert (Eds.). The Oxford handbook of cognitive linguistics. Nova York; Oxford: Oxford University Press, 2007, p. 1241-1265.

HARRIS, Randy Allen. The linguistics wars. Nova York; Oxford: Oxford University Press, 1993.

JACKENDOFF, Ray. Alternative minimalist visions of language. In: BORSLEY, Robert D.; BÖRJARS, Kersti. Non-transformational syntax: formal and explicit models of grammar. Chichester, West Sussex, UK; Malden, MA: Wiley-Blackwell, 2011a, p. 268-296.

JACKENDOFF, Ray. Foundations of language: brain, meaning, grammar, evolution. Oxford; Nova York: Oxford University Press, 2003.

JACKENDOFF, Ray. Genesis of a theory of language: from thematic roles (source) to the parallel architecture (goal) (sort of an intellectual memoir), 2014. Disponível em: <https://ase.tufts.edu/cogstud/jackendoff/papers/GenesisofPA.pdf>. Acesso em: 2 nov. 2018.

JACKENDOFF, Ray. Language, consciousness, culture: essays on mental structure. Cambridge, Mass: MIT Press, 2007.

JACKENDOFF, Ray. Patterns in the mind: language and human nature. Nova York: Harvester Wheatsheaf, 1993.

JACKENDOFF, Ray. Semantic interpretation in generative grammar. Cambridge, MA: MIT Press, 1980.

JACKENDOFF, Ray. The architecture of the language faculty. Cambridge, MA: MIT Press, 1997.

JACKENDOFF, Ray. The parallel architecture and its place in cognitive science. In: HEINE, Bernd; NARROG, Heiko (Eds.). The Oxford handbook of linguistic analysis. Oxford: Oxford University Press, 2010, p. 583-605. 
JACKENDOFF, Ray. What is the human language faculty? Two views. Language, v. 87, n. 3, p. 586-624, $2011 b$.

JENKINS, Lyle. Biolinguistics: a historical perspective. In: BOECKX, Cedric; GROHMANN, Kleanthes K. The Cambridge handbook of biolinguistics. Cambridge: Cambridge University Press, 2013, p. 4-11.

KATZ, Jerrold; POSTAL, Paul. An integrated theory of linguistic descriptions. Cambridge, MA: MIT Press, 1964.

LANGACKER, Ronald W. Cognitive grammar. In: GEERAERTS, Dirk; CUYCKENS, Hubert (Eds.). The Oxford handbook of cognitive linguistics. Nova York; Oxford: Oxford University Press, 2007, p. 421-462.

LANGACKER, Ronald W. Cognitive grammar: a basic introduction. Oxford; Nova York: Oxford University Press, 2008.

LANGACKER, Ronald W. Cognitive grammar. In: HEINE, Bernd; NARROG, Heiko (Eds.). The Oxford handbook of linguistic analysis. Oxford: Oxford University Press, 2010, p. 87-109.

LANGACKER, Ronald W. Concept, image, and symbol: the cognitive basis of grammar. Berlim; Nova York: Mouton de Gruyter, 1991a.

LANGACKER, Ronald W. Conceptualization, symbolization, and grammar. In: TOMASELLO, Michael (Ed.). The new psychology of language: cognitive and functional approaches to language structure. Mahwah; Londres: Lawrence Erlbaum Associates, Publishers, 1998, p. 1-39.

LANGACKER, Ronald W. Construction grammar: cognitive, radical, and less so. In: RUIZ DE MENDOZA IBÁÑEZ, Francisco José; PEÑA CERVEL, M. Sandra. Cognitive linguistics: internal dynamics and interdisciplinary interaction. Berlim; Nova York: Mouton de Gruyter, 2005, p. 101159.

LANGACKER, Ronald W. Essentials of cognitive grammar. Oxford: Oxford University Press, 2013.

LANGACKER, Ronald W. Foundations of cognitive grammar. Volume 1: Theoretical prerequisites. Stanford: Stanford University Press, 1987.

LANGACKER, Ronald W. Foundations of cognitive grammar. Volume 2: Descriptive application. Stanford: Stanford University Press, 1991b.

LANGACKER, Ronald W. The integration of grammar and grammatical change. Indian Linguistics, v. 42, p. $82-135,1981$.

LAKATOS, Imre. O falseamento e a metodologia dos programas de pesquisa científica. In: LAKATOS, Imre; MUSGRAVE, Alan. (Orgs.). A crítica e o desenvolvimento do conhecimento: quarto volume das atas do Colóquio Internacional sobre Filosofia da Ciência, realizado em Londres em 1965. São Paulo: Cultrix, 1979, p. 109-243.

LAKATOS, Imre. Philosophical papers. Volume 1: The methodology of scientific research programmes. Cambridge: Cambridge University Press, 1995.

LAKOFF, George. Cognitive phonology. In: GOLDSMITH, John (Ed.). The last phonological rule. Chicago: University of Chicago Press, 1993, p. 117-145.

LAKOFF, George; JOHNSON, Mark. Metaphors we live by. Chicago; Londres: The University of Chicago Press, 2003.

LEMLE, Miriam. Análise sintática: teoria geral e descrição do português. São Paulo: Ática, 1984.

LENNEBERG, Eric H. Biological foundations of language. Nova York: Wiley \& Sons, 1967.

MARCUS, Gary F.; RABAGLIA, Cristina D.; RABAGLIATI, Hugh. Modularity and descente-withmodification. In: BOECKX, Cedric; GROHMANN, Kleanthes K. The Cambridge handbook of biolinguistics. Cambridge: Cambridge University Press, 2013, p. 326-340.

MARR, David. Vision: a computational investigation into the human representation and processing of visual information. San Francisco: W. H. Freeman and Co., 1982.

MARSHALL, John C. Foreword. In: YAMADA, Jeni E. Laura: a case for the modularity of language. Cambridge, Mass: MIT Press, 1990, p. vii-xi.

MILlOTTE, Séverine; CAUVET, Elodie; BRUSINI, Perrine; CHRISTOPHE, Anne. Discovering word forms and word meanings: the role of phrasal prosody and function words. In: BOECKX, Cedric; GROHMANN, Kleanthes K. The Cambridge handbook of biolinguistics. Cambridge: Cambridge University Press, 2013, p. 86-93.

NATHAN, Geoff. Phonology. In: GEERAERTS, Dirk; CUYCKENS, Hubert (Eds.). The Oxford handbook of cognitive linguistics. Nova York; Oxford: Oxford University Press, 2007, p. 611-631.

NATHAN, Geoff. Phonology: a cognitive grammar introduction. Amsterdã: John Benjamins Publishing, 2008. 
NERLICH, Brigitte; CLARKE, David D. Cognitive linguistics and the history of linguistics. In: GEERAERTS, Dirk; CUYCKENS, Hubert (Eds.). The Oxford handbook of cognitive linguistics. Nova York; Oxford: Oxford University Press, 2007, p. 589-607.

NERLICH, Brigitte; CLARKE, David D. Mind, meaning, and metaphor: the philosophy and psychology of metaphor in nineteenth-century Germany. History of the Human Sciences, v. 14, p. 39-61, 2001.

NERLICH, Brigitte; CLARKE, David D. Semantic fields and frames: historical explorations of the interface between language, action and cognition. Journal of Pragmatics, v. 32, p. 125-150, 2000.

NEWMEYER, Frederick J. Generative linguistics: a historical perspective. Londres; Nova York: Routledge, 1996.

NUYTS, Jan. Cognitive linguistics and functional linguistics. In: GEERAERTS, Dirk; CUYCKENS, Hubert (Eds.). The Oxford handbook of cognitive linguistics. Nova York; Oxford: Oxford University Press, 2007, p. 543-565.

PARRET, Herman. Discussing language. Haia: Mouton, 1974.

PAUL, Hermann. Princípios fundamentais da história da língua. 2. ed. Lisboa: Fundação Calouste Gulbenkian, 1983.

PIAGET, Jean. Play, dreams and imitation in childhood. Nova York: Norton, 1952.

PIAGET, Jean. The construction of reality in the child. Nova York: Ballantine, 1971.

PIAGET, Jean. The language and thought of the child. 3. ed. Londres: Routledge \& Kegen Paul, 1975.

PIATTELLI-PALMARINI, Massimo. Biolinguistics yesterday, today, and tomorrow. In: BOECKX, Cedric; GROHMANN, Kleanthes K. The Cambridge handbook of biolinguistics. Cambridge: Cambridge University Press, 2013, p. 12-21.

PIATTELLI-PALMARINI, Massimo. Teorias da linguagem, teorias da aprendizagem: o debate entre Jean Piaget \& Noam Chomsky. São Paulo: Cultrix; Editora da Universidade de São Paulo, 1983.

PIATTELI-PALMARINI, Massimo; BERWICK, Robert C. (Eds). Rich languages from poor inputs. Oxford: Oxford University Press, 2013.

PINKER, Steven. Language learnability and language development. Cambridge, MA: Harvard University Press, 1984.

PINKER, Steven. Learnability and cognition: the acquisition of verb-argument structure. Cambridge, MA: Harvard University Press, 1989.

POSTAL, Paul. The best theory. In: PETERS, Stanley (Ed.). Goals of linguistic theory. Englewood Cliffs: Prentice-Hall, 1972, p. 131-170.

PRINCE, Alan; SMOLENSKY, Paul. Optimality theory: constraint interaction in generative grammar. Rutgers University Center for Cognitive Science, Technical report n. 2, 1993.

SCHRÖDER, Ulrike A. A abordagem cognitiva da metáfora em perspectiva pragmática nos séculos dezoito e dezenove: as contribuições de Lambert e Wegener a discussões atuais. Alfa, v. 58, n. 1, p. 115136, 2014.

SCHRÖDER, Ulrike Antecipações da metáfora cotidiana nas concepções de Hans Blumenberg e Harald Weinrich. Revista de Estudos da Linguagem, Belo Horizonte, v. 16, n. 2, p. 39-54, jul./dez. 2008.

SCHRÖDER, Ulrike Os precursores filosóficos da teoria cognitiva das metáforas. Cadernos de Estudos Linguísticos, Campinas, v. 46, n. 2, p. 243-252, jul/dez. 2004.

SCHRÖDER, Ulrike Uma volta para as fundamentações filosóficas de uma teoria cognitiva da metáfora. Domínios de Lingu@gem, Uberlândia, v. 11, p. 34-62, 2017.

SILVA, Augusto Soares da. A linguística cognitiva: uma breve introdução a um novo paradigma em linguística. Revista Portuguesa de Humanidades, v. 1, n. 1-2, p. 59-101, 1997.

SILVA, Gustavo Augusto Fonseca. Reflexões sobre a linguística galileana de Noam Chomsky. Revista de Estudos da Linguagem, v. 28, n. 1, p. 93-158, 2020.

SILVA, Gustavo Augusto Fonseca. 40 anos de Metaphors we live by: considerações sobre a teoria das metáforas conceituais de Lakoff e Johnson. Revista de Estudos da Linguagem, v. 29, n. 1, p. 153214, 2021.

SINANOVIĆ, Osman; MRKONJIĆ, Zamir; ZUKIĆ, Sanela; VIDOVIĆ, Mirjana; IMAMOVIĆ, Kata. Post-stroke language disorders. Acta Clinica Croatia, v. 50, n. 1, p. 79-94, 2011.

SMITH, Neil; TSIMPLI, Ianthi-Maria. The mind of a savant: language learning and modularity. Oxford; Cambridge, Mass: Blackwell, 1995.

TALMY, Leonard. Toward a cognitive semantics. Cambridge, Massachusetts: MIT Press, 2000. $2 \mathrm{v}$.

TAYLOR, John R. Cognitive linguistics and autonomous linguistics. In: GEERAERTS, Dirk; CUYCKENS, Hubert (Eds.). The Oxford handbook of cognitive linguistics. Nova York; Oxford: Oxford University Press, 2007, p. 566-588.

TAYLOR, John R. Linguistic categorization. 3. ed. Oxford; Nova York: Oxford University Press, 2003. 
TRAXLER, Matthew J.; GERNSBACHER, Morton Ann (Eds.). Handbook of psycholinguistics. 2. ed. Amsterdã; Boston: Elsevier/Academic Press, 2006.

UNGERER, Friedrich; SCHMID, Hans-Jörg. An introduction to cognitive linguistics. Londres; Nova York: Longman, 1996.

UNTERBECK, Barbara; RISSANEN, Matti; NEVALAINEN, Terttu; SAARI, Mirja (Eds). Gender in grammar and cognition. Berlim; Nova York: Mouton de Gruyter, 2000.

VÄLIMAAN-BLUM, Riitta. Cognitive phonology in construction grammar: analytic tools for students of English. Berlim; Nova York: Mouton de Gruyter, 2005.

YAMADA, Jeni E. Laura: a case for the modularity of language. Cambridge, Mass: MIT Press, 1990.

Recebido: 1/10/2019

Aceito: 6/2/2021

Publicado: 9/2/2021 